\title{
3. COVID-19 is exacerbating inequalities in food security
}

\section{Johan Swinnen}

COVID-19 is disrupting economies and food systems everywhere, but the poor will suffer the greatest risk of food crisis. Based on model predictions, early empirical evidence, and lessons from previous crises, it is clear that the risk of increased food insecurity depends on the level of economic development. As employment and income opportunities fall for the poor, the gap between rich and poor is growing. Among the poor, urban poor and women are especially vulnerable.

The poor's food and nutrition security will be disproportionately impacted by COVID-19 because:

1. The global economic recession will have larger effects on poor people's incomes.

2. The poor spend a larger share of their income on food.

3. Among productive assets, physical labor - poor people's principal asset - will be most affected by COVID-19.

4. COVID-19 will cause more disruptions in private sector value chains in poor countries.

5. COVID-19 will cause disruptions in public sector programs for food, nutrition, health, and poverty, which are more important for poor people.

6. The poor have less access to sanitation facilities and healthcare.

7. Poor countries have lower economic capacities to compensate for declining incomes.

Economic models predict that under current conditions - relatively high food stocks, good harvests, low oil prices, and declining demand - global food prices are not going to rise. However, logistical problems in harvesting and transport will put upward pressure on food prices in some areas of the world. Paradoxically, the most important cause of rising food prices may be hoarding behavior by consumers and governments rather than market conditions. Despite several expert reports and economic advice not to repeat the same errors made during the 2007-2008 food crisis, many governments early on introduced trade constraints for foods (see IFPRI's Food Export Restrictions Tracker). Yet even absent a major rise in food prices, the food security situation of poor people is likely to decline significantly around the world. 


\section{Falling incomes and food and nutrition security}

The global recession, caused by lockdowns and other restrictions on business activity to control COVID-19, leads to reductions in food consumption and declines in nutrition status - especially among the poor. Whether through rising food prices, falling incomes, or both, people have less real income to pay for their food and will adjust accordingly. This effect plays out more strongly the less income one has, meaning more hardship for the poor. Global models predict that for every percentage point of global economic slowdown, the number of people living in poverty would increase by $2 \%$ to $3 \%$, or about 14 to 23 million worldwide. However, health and economic impacts may be much more pronounced in developing, rather than developed, countries with associated greater implications for poverty and hunger.

An early study by Rozelle et al. (2020) confirms these effects for rural households in China. Separated from their income sources as COVID-19 travel restrictions prevented them from working in urban wage jobs, workers suffered massive income losses totaling more than $\$ 100$ billion. These families cut back significantly on nutrition. The majority of villagers are reducing spending on food, buying more grains and staples in bulk at low cost instead of more expensive goods like meat and produce.

Other early evidence confirms the disproportionate impact on the poor. Hirvonen et al. (2020) find that significant declines in incomes were greatest among the poor in Ethiopia; and Tesfaye et al. (2020) find that the decline in nutritious food in Ethiopia was also more important among the poor.

COVID-19 impacts the poorest particularly hard because it directly affects their most important, sometimes only, productive asset: labor, especially physical labor. Richer people typically have a portfolio of productive assets, such as capital and land, and their labor is typically of a different quality. Even while locked down inside a townhouse or a city apartment, they can work via computer over the internet, spending their productive hours on email and Zoom. This is not the case for poor people with low skills whose only source of income is likely to entail leaving home to do manual work.

Within the group of "the poor," women and urban consumers particularly seem to suffer more. Quisumbing et al. identify several reasons for the gendered impact of COVID-19. A series of recent country studies by IFPRI researchers, summarized in Thurlow (2020), shows how urban poor who have lost their jobs and face the same or higher food prices are particularly negatively affected.

Another group of poor people that are among the hardest-hit by COVID-19 restrictions are those who have to travel for work. Studies show large negative effects for migrant workers in several categories: rural-urban (as in China-see Rozelle et al. 2020), international (as in Egypt-see Breisinger et al. 2020; and Myanmar-see Diao and Wang 2020), or rural-rural (as in India, where landless workers travel to work in seasonal jobs such as harvesting-see Dev 2020).

\section{Disruption of private value chains}

Harvesting may be disrupted because of a lack of workers; planting because of a lack of seed or fertilizer; transport because of reduced transport facilities; and market exchange because of lockdowns or social distancing. What we are witnessing is a disruption of the food system similar to what happened during 1990s-era transition processes when supply chains collapsed. Those experiences showed that impacts were strongly heterogeneous, depending on the nature of the commodity, the resource-intensity of the systems, and the level of economic development. 
But in the 1990s, the key production factor affected was capital (see Rozelle and Swinnen 2004). Today, as noted, the disruption is mostly related to labor constraints. As a consequence, capital-intensive food value chains (mostly in rich countries, or in richer parts of poor countries) are much less affected than labor-intensive value chains (mostly in poor countries). Reardon et al. (2020) point out that the impacts will be greatest in informal-sector small and medium-sized enterprises, which are labor-intensive with high densities of workers in small spaces. Modern retail and food-service firms face fewer problems. Again, these differences are affecting food security among the poor disproportionately.

\section{Disruptions in public sector programs and less access to health and sanitation facilities}

COVID-19 will cause disruptions in public sector programs for food, nutrition, health, and poverty, which poor people depend on. For instance, India's national lockdown regulations implied closing of schools. This means that school feeding programs - one of the country's largest safety nets - have been suspended. Other safety nets are also affected, including nutrition programs in community courtyard sessions for pregnant women and lactating mothers. Key health programs, such as child immunization, have been disrupted as well. And of course, public food relief programs face the risk of exposing more people to the virus by attracting large crowds at distribution points.

These disruptions affect the poor disproportionately. They compound the problems associated with unequal access to sanitation facilities, including basic facilities such as running water, which is crucial for protection against COVID-19, and limited access to healthcare. Good healthcare institutions are less available in poor countries in general and access to them is particularly limited for the poor.

\section{Limited government capacity to compensate}

While many developed countries have responded to the economic fallout from COVID-19 by ramping up spending and using monetary policies, options for developing countries may be more limited. Developing countries will need to prioritize, focusing their responses on health, essential goods and services, the domestic financial circuit in local currency, and the foreign currency market linked to international trade and external debt. Such a focused approach can help finance public spending on programs like cash transfers and safety nets for the poor and vulnerable, and public investments to keep firms operating. At the same time, the international community also has a crucial role to play in supporting countries in their policy responses, including through international organizations like the World Bank, United Nations, and IMF, as well as the multilateral development banks.

In summary, several compounding factors mean that COVID-19 is likely to cause another major food crisis among the poor. To avoid a food crisis, governments will need to implement policies and programs that target those most impacted and help address the negative impacts.

Originally published April 10,2020, and updated June 20,2020. This post also appears on the Global Alliance for Improved Nutrition (GAIN) Nutrition Connect blog. 